\title{
Antimicrobial Sensitivity Profile of Eye Infection in Dogs
}

\author{
Sisir Das ${ }^{1 *}$, Rajashree Mishra ${ }^{1}$, Prasana Kumar Rath ${ }^{2}$, Bidyutprava Mishra $^{3}$, \\ Chinmoy Mishra ${ }^{4}$ and S.S. Behera ${ }^{1}$ \\ ${ }^{1}$ Department of Veterinary Microbiology, College of Veterinary Science and Animal \\ Husbandry, OUAT, Bhubaneswar- (751 003), India \\ ${ }^{2}$ Department of Veterinary Pathology, College of Veterinary Science and Animal Husbandry, \\ OUAT, Bhubaneswar- (751 003), India \\ ${ }^{3}$ Department of Livestock Production Technology, College of Veterinary Science and Animal \\ Husbandry, OUAT, Bhubaneswar- (751 003), India \\ ${ }^{4}$ Department of Animal Breeding and Genetics, College of Veterinary Science and Animal \\ Husbandry, OUAT, Bhubaneswar-(751 003), India \\ *Corresponding author
}

\section{A B S T R A C T}

In the present study 88 number of corneal swabs were collected from 8 different breeds of dog suffering from corneal diseases. All the dogs were presented to Teaching Veterinary Clinical Complex of Odisha Veterinary College for treatment during the period from December 2018 to June

\begin{tabular}{|l|}
\hline K e y w o r d s \\
$\begin{array}{l}\text { Eye, Antimicrobial } \\
\text { susceptibility, Dog }\end{array}$ \\
\hline Article Info \\
\hline $\begin{array}{l}\text { Accepted: } \\
\text { 07 July 2019 } \\
\text { Available Online: } \\
\text { 10 August } 2019\end{array}$ \\
\hline
\end{tabular}
2019. The breeds consists of Non-descript $(n=18)$, Pug $(n=11)$, Labrador $(n=10)$, German shepherd $(n=12)$, Spitz $(n=14)$, Golden retriever $(n=10)$, Dalmatian $(n=7)$, and Mastiff $(n=6)$. There were no history of injury of the eye prior to infection and all most all the dogs were naturally infected with various microbial agents. In order to identify the microbial isolates and its antimicrobial susceptibility profile all the isolates were subjected to routine microbial procedure. Out of 246 number of bacterial isolates, the most commonly isolated bacteria were Staphylococcus spp. (35\%) followed by Streptococcus spp (27\%), Pseudomonas spp. (26\%), and E. Coli (10\%). The antimicrobial susceptibility test was done by disk diffusion method in which ciprofioxacin, cephalexin, neomycin and amoxycillin/clavulanic acid was sensitive to Staphylococcus spp., cephalexin, chloramphenicol and amoxycillin/clavulanic acid was sensitive to Streptococcus spp. and amikacin, gentamicin and tobramycin was found to be highly sensitive to Pseudomonas spp. Similarly, out of 115 fungal isolates, the most commonly fungal isolates were found to be Aspergillus spp. (40\%) and Candida spp (59\%), whereas mixed fungal infection were found to be prominant. Antifungals like fluconazole, voriconazole and miconazole were found to be sensitive to Aspergillus spp. as well as Candida spp.

\section{Introduction}

Ocular infectious disease by microorganisms is a major cause of corneal opacity and loss of vision in dogs. The normal cornea prevents bacterial invasion by various anatomical, mechanical, immunological and microbiological mechanisms. Failure of these defenses may contribute to ulcerative keratitis and predispose the cornea to bacterial infection. The eye is remarkably resistant to constant bombardment of potentially pathogenic microorganisms. At the level of 
cornea, the defense against bacterial invasion is determined by the integrity of anatomical barriers and the associated immune status of the host, disruption of which induces bacterial invasion. Sloughing of epithelial cells of cornea and conjuctiva and precorneal tearfilm (lysozyme, lactoferrin etc.) also plays an important role in preventing the bacterial infection.

The normal microbial population of the ocular surface is believed to interfere with invading organisms by depriving them of nutrients and secreting substances with antimicrobial properties. Destruction of normal ocular flora by long-term use of topical antimicrobials or corticosteroids can result in overgrowth of pathogenic bacteria, yeast and fungi (Franck, 2003). Fungal keratitis is reported less frequently in the dog than some other animal species but can be associated with substantial ocular morbidity and vision loss (Pucket et al., 2012).

The objectives of this study is to isolate and identify the causative organism causing ocular infection in dogs and to determine antimicrobial sensitivity pattern.

\section{Materials and Methods}

In the present study a total number of 88 samples from different breeds like Nondescript (18), Pug (11), Labrador (10), German Shepherd (12), Spitz (14), Golden Retriever (10), Dalmatian (7), and Mastiff (6) were collected from dogs presented to Teaching Veterinary Clinical Complex for treatment OUAT, Bhubaneswar during the period from December, 2018 to June, 2019. The samples were collected in sterile cotton swab moistened with 1-2 drops of sterile normal saline solution $(0.9 \% \mathrm{NaCl})$ (Hindley et al., 2016). Duplicate samples were collected from each animal.

\section{Microbial analysis}

For bacterial isolation, the samples were inoculated in standard broth like Brain Heart Infusion (BHI) broth and incubated overnight at $37^{\circ} \mathrm{C}$. Then identification of the bacteria was done by routine isolation techniques using Gram's staining and culture media. Samples were inoculated in various selective media like McConkey lactoseagar (MLA), blood agar (BA), mannitol salt agar (MSA), pseudomonas isolation agar (PIA) and incubated for $24 \mathrm{hr}$ at $37^{\circ} \mathrm{C}$. Then motility, colony morphology with reference to colony size, colour and nature of colony, were studied along with various biochemical tests (Stephen et al., 2010) for identification.

\section{Mycological analysis}

The samples were inoculated into sabouraud dextrose agar (SDA) and potato dextrose agar (PDA). The plates were incubated at $37^{\circ} \mathrm{C}$ for 3-4 days. Identification of the fungus was done by observing colony morphology with reference to colour, hyphae and nature of colony. Microscopic examination was done by Lactophenol cotton blue staining and Gram staining.

\section{Antibiogram study}

Muller Hinton Agar (MHA) obtained from M/S Hi-Media Laboratories Ltd. Mumbai was employed for the in-vitro antibiotic sensitivity test of bacterial isolates as per the commonly used disk diffusion method Bauer et al., (1966) and the zone of inhibition was recorded.

The antibiotic discs used for bacterial isolation were ciprofloxacin (30mcg), cephalexin (30mcg), gentamicin (10mcg), polymyxin B (300 mcg), neomycin (30 mcg), chloramphenicol (30mcg), tobramycin (30mcg), amikacin (30 mcg), 
amoxycilli/clavulanic acid (30mcg) whereas, antifungal discs used were fluconazole (10 $\mathrm{mcg}$ ), voriconazole $(1 \mathrm{mcg})$ and mionazole (30mcg). Muller Hinton Agar (MHA) along with $2 \%$ glucose and $0.5 \mathrm{mcg} / \mathrm{ml}$ methylene blue (CLSI) were used for antifungal sensitivity test as per guideline. All the antifungal and antibiotic discs were obtained from HiMedia, Mumbai, India. The results were interpreted according to criteria set by Clinical and Laboratory Standards Institute (CLSI) (Wayne, 2009).

\section{Result and Discussion}

In the present study, out of 88 eye swabs collected, 246 number of bacterial isolates and 115 number of fungal isolates were obtained by routine microbial isolation. Staphylococcus spp. (87/246, 35\%) was found as the most predominant bacterial isolate (Lin and Jones, 2007) followed by Streptococcus spp. (68/246, 27\%), Pseudomonas spp. (66/246, 26\%) and E.Coli (25/246, 10\%). Similarly, Candida spp. $(68 / 115,59 \%)$ was the predominant fungal isolate followed by Aspergillus spp. (47/115, $40 \%$ ) which shows $29 \%$ of fungal infection out of total microbial isolates. This result is similar to that of study of Samuelson et al., (1984).

The distribution of various microbial isolates are depicted in Table 1 . Out of total 246 number of bacterial isolates, 155/246 (63\%) were found gram positive and 91/246 (36.9\%) were found to be gram negative isolates. Most of the above organisms are ubiquitous and indigenous microflora of corneal and conjuctival surface (Furiani, 2011). Weak defense mechanism of the cornea may predisposes the animal to this infection. Macroscopically Pseudomonas aeruginosa produces flurescin pigment (greenish colour) on Pseudomonas Isolation Agar media as well as on MHA plate, $\beta$-hemolysis was shown by Streptococcus spp. on blood agar plates, pink colour colony was produced by E.Coli on McConkey lactose agar. Similarly, Aspergillus spp. produces characteristic velvety or wooly yellowish green colonies whereas Candida spp. produces whitish, shiny and convex colonies of 4 to $5 \mathrm{~mm}$ in diameter after incubation for 3-4 days on SDA plate. On lactophenol cotton blue staining, club shaped vesicle with uniseriate conidia was identified as Aspergillus spp. and budding yeast cells (blastoconidia) were found on gram staining. Candida spp. were found to be gram positive.

On analysis of antibiogram susceptibility pattern produced by various anbiotics and antifungals, it was found that Staphylococcu spp. was highly sensitive to cephalexin, neomycin, ciprofloxacin and amoxycillin/clavulanic acid. Streptococcus spp. were sensitive to cephalexin, chloramphenicol and amoxycillin/clavulanic acid.

Pseudomonas spp. isolates were sensitive to ciprofloxacin, gentamicin, amikacin and tobramycin whereas E. Coli isolates were susceptible to ciprofloxacin and amikacin. This study is in agreement with the study of Hindley et al., (2016) and Lin et al., (2007). Similarly, both the Aspergillus spp. and Candida spp. isolates were susceptible to fluconazole, voriconazole and miconazole (Stacy et al., 2003). The detail antimicrobial profile is depicted in Table 2.

In case of Staphylococcus spp. antibiotics like ciprofloxacin, cephalexin, gentamicin, polymyxin B, neomycin, chloramphenicol, amoxycillin/clavulanic acid showed minimum inhibitory zone of 22, 20, 15, 8, 17, 17 and 18 mm respectively. In case of Pseudomonas spp. ciprofloxacin, cephalexin, gentamicin, polymyxin B, neomycin, chloramphenicol, tobramycin and amikacin showed minimum inhibitory zone of $21,10,16,12,14,12,15$ and $17 \mathrm{~mm}$ respectively. 
Int.J.Curr.Microbiol.App.Sci (2019) 8(8): 505-511

Table.1 Shows the distribution of various micrbial isolates collected from 88 number of corneal swabs of dog

\begin{tabular}{|c|c|c|c|c|c|c|c|c|}
\hline $\begin{array}{l}\text { Sl } \\
\text { no. }\end{array}$ & $\begin{array}{c}\text { Name of the dog } \\
\text { breed }\end{array}$ & $\begin{array}{l}\text { No. of corneal } \\
\text { swab collected }\end{array}$ & $\begin{array}{c}\text { Staphylococcus } \\
\text { spp. }\end{array}$ & $\begin{array}{l}\text { Streptococcus } \\
\text { spp. }\end{array}$ & $\begin{array}{l}\text { Pseudomonas } \\
\text { spp. }\end{array}$ & E. coli & $\begin{array}{c}\text { Aspergillus } \\
\text { spp. }\end{array}$ & Candida spp. \\
\hline 01 & Non-descript & 18 & 18 & 18 & 15 & 6 & 11 & 16 \\
\hline 02 & Pug & 11 & 11 & 7 & 9 & 3 & 8 & 9 \\
\hline 03 & Labrador & 10 & 10 & 8 & 8 & 3 & 7 & 6 \\
\hline 04 & German shepeherd & 12 & 12 & 7 & 7 & 3 & 7 & 9 \\
\hline 05 & Spitz & 14 & 14 & 10 & 10 & 5 & 5 & 8 \\
\hline 06 & Golden Retriver & 10 & 9 & 7 & 8 & 2 & 4 & 9 \\
\hline 07 & Dalmatian & 7 & 7 & 5 & 5 & 1 & 3 & 5 \\
\hline 08 & Mixed & 6 & 6 & 6 & 4 & 2 & 2 & 6 \\
\hline & Total & 88 & 87 & 68 & 66 & 25 & 47 & 68 \\
\hline
\end{tabular}


Table. 2 Shows the antimicrobial and antifungal profile of eye infection in dogs $(n=88)$

\begin{tabular}{|c|c|c|c|c|c|c|c|c|c|c|c|c|}
\hline \multirow{2}{*}{$\begin{array}{l}\text { Name of microbial } \\
\text { isolates }\end{array}$} & \multicolumn{12}{|c|}{ Number susceptible/total numer of isolates tested to antimicrobials with percentage } \\
\hline & CIP & $\mathrm{CN}$ & GEN & PB & $\mathrm{N}$ & $\mathrm{C}$ & TOB & AK & AMC & FLU & VCZ & $\mathrm{MIC}$ \\
\hline $\begin{array}{l}\text { Staphylococcus spp. } \\
(\mathbf{n}=\mathbf{8 7})\end{array}$ & $\begin{array}{l}87 / 87 \\
(100 \%)\end{array}$ & $\begin{array}{c}87 / 87 \\
(100 \%)\end{array}$ & $\begin{array}{l}73 / 87 \\
(85 \%)\end{array}$ & $\begin{array}{l}10 / 87 \\
(12 \%)\end{array}$ & $\begin{array}{l}87 / 87 \\
(100 \%)\end{array}$ & $\begin{array}{l}73 / 87 \\
(85 \%)\end{array}$ & - & - & $\begin{array}{l}80 / 87 \\
(92 \%)\end{array}$ & - & - & - \\
\hline $\begin{array}{l}\text { Streptococcus spp. } \\
(n=68)\end{array}$ & $\begin{array}{l}11 / 68 \\
(16 \%)\end{array}$ & $\begin{array}{c}68 / 68 \\
(100 \%)\end{array}$ & $\begin{array}{l}0 / 68 \\
(0 \%)\end{array}$ & $\begin{array}{l}0 / 68 \\
(0 \%)\end{array}$ & $\begin{array}{l}0 / 68 \\
(0 \%)\end{array}$ & $\begin{array}{l}68 / 68 \\
(100 \%)\end{array}$ & - & - & $\begin{array}{l}60 / 68 \\
(89 \%)\end{array}$ & - & - & - \\
\hline $\begin{array}{l}\text { Pseudomonas spp. } \\
(\mathrm{n}=66)\end{array}$ & $\begin{array}{c}66 / 66 \\
(100 \%)\end{array}$ & $\begin{array}{l}0 / 66 \\
(0 \%)\end{array}$ & $\begin{array}{c}66 / 66 \\
(100 \%)\end{array}$ & $\begin{array}{l}59 / 66 \\
(90 \%)\end{array}$ & $\begin{array}{l}14 / 66 \\
(22 \%)\end{array}$ & $\begin{array}{l}0 / 66 \\
(0 \%)\end{array}$ & $\begin{array}{c}66 / 66 \\
(100 \%)\end{array}$ & $\begin{array}{c}66 / 66 \\
(100 \%)\end{array}$ & - & - & - & - \\
\hline E.coli $(\mathbf{n}=25)$ & $\begin{array}{l}12 / 25 \\
(50 \%)\end{array}$ & - & $\begin{array}{l}8 / 25 \\
(33 \%)\end{array}$ & $\begin{array}{l}8 / 25 \\
(33 \%)\end{array}$ & $\begin{array}{l}4 / 25 \\
(16 \%)\end{array}$ & $\begin{array}{l}8 / 25 \\
(33 \%)\end{array}$ & $\begin{array}{l}8 / 25 \\
(33 \%)\end{array}$ & $\begin{array}{l}16 / 25 \\
(67 \%)\end{array}$ & - & - & - & - \\
\hline $\begin{array}{l}\text { Aspergillus spp. } \\
(\mathrm{n}=47)\end{array}$ & - & - & - & - & - & - & - & - & - & $\begin{array}{c}47 / 47 \\
(100 \%)\end{array}$ & $\begin{array}{c}47 / 47 \\
(100 \%)\end{array}$ & $\begin{array}{c}47 / 47 \\
(100 \%)\end{array}$ \\
\hline Candida spp. $(\mathrm{n}=68)$ & & & & & & & & & & $\begin{array}{c}68 / 68 \\
(100 \%)\end{array}$ & $\begin{array}{c}68 / 68 \\
(100 \%)\end{array}$ & $\begin{array}{c}68 / 68 \\
(100 \%)\end{array}$ \\
\hline
\end{tabular}

CIP = Ciprofloxacin, $\mathrm{CN}=$ Cephalexin, GEN = Gentamicin, $\mathrm{PB}=$ Polymyxin $\mathrm{B}, \mathrm{N}=$ Neomycin, $\mathrm{C}=\mathrm{Chloramphenicol}$, TOB = Tobramycin, AK = Amikacin, $\mathrm{AMC}=$ Amoxycillin Clavulanic acid, FLU = Fluconazole. $\mathrm{VCZ}=$ Voriconazole, $\mathrm{MIC}=$ Miconazole

*Not all antimicrobial agents were tested against each microbial isolates.

Table.3 Shows the diameter of zone of inhibition $(\mathrm{mm})$ of various antimicrobials against each microbial isolates of eye infection in $\operatorname{dogs}(n=88)$

\begin{tabular}{|c|c|c|c|c|c|c|c|c|c|c|c|c|}
\hline \multirow{2}{*}{ 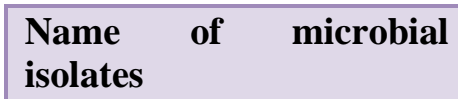 } & \multicolumn{12}{|c|}{ Diameter of zone of inhibition in $\mathrm{mm}$} \\
\hline & CIP & $\mathrm{CN}$ & GEN & PB & $\mathrm{N}$ & $\mathrm{C}$ & TOB & AK & AMC & FLU & VCZ & MIC \\
\hline Streptococcus spp. & 19 & 19 & 11 & - & 11 & 18 & - & - & 18 & - & - & - \\
\hline E.coli & 20 & - & 13 & 10 & 14 & 16 & 13 & 17 & - & - & - & - \\
\hline Aspergillus spp. & - & - & - & - & - & - & - & - & - & 20 & 17 & 27 \\
\hline Candida spp. & & & & & & & & & & 22 & 18 & 26 \\
\hline
\end{tabular}

$\mathrm{CIP}=$ Ciprofloxacin, $\mathrm{CN}=$ Cephalexin, GEN = Gentamicin, $\mathrm{PB}=$ Polymyxin $\mathrm{B}, \mathrm{N}=$ Neomycin, $\mathrm{C}=$ Chloramphenicol, $\mathrm{TOB}=\mathrm{Tobramycin}, \mathrm{AK}=\mathrm{Amikacin}$, $\mathrm{AMC}=$ Amoxycillin Clavulanic acid, $\mathrm{FLU}=$ Fluconazole $. \mathrm{VCZ}=$ Voriconazole, $\mathrm{MIC}=$ Miconazole

*Not all antimicrobials were tested against all microbial isolates. 


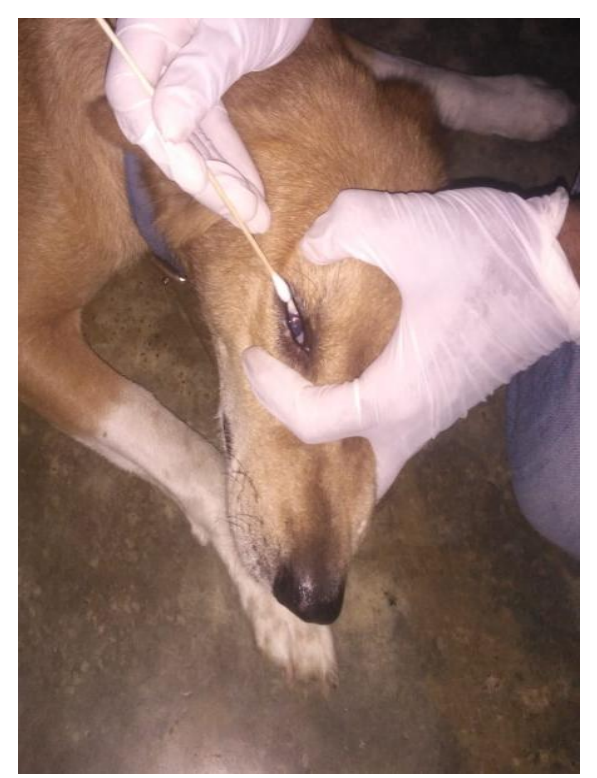

Fig.1 Collection of sample from nondescriptive breed

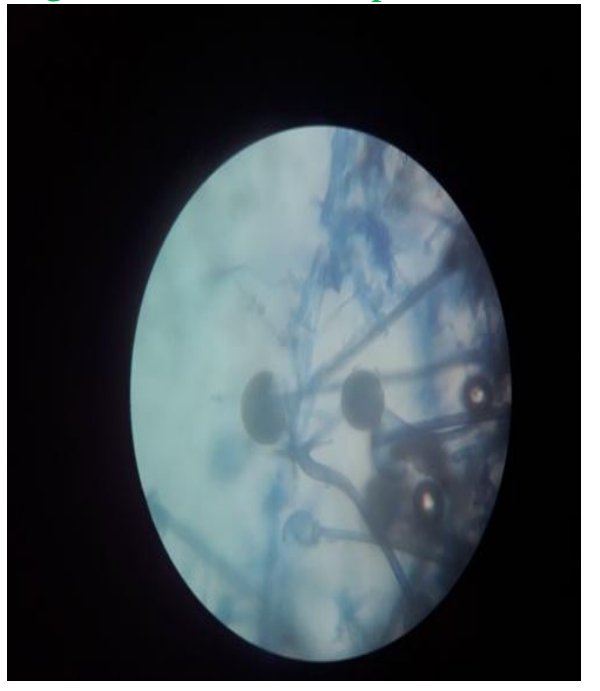

Fig.3 Aspergillus spp. on Lactophenol cotton blue staining

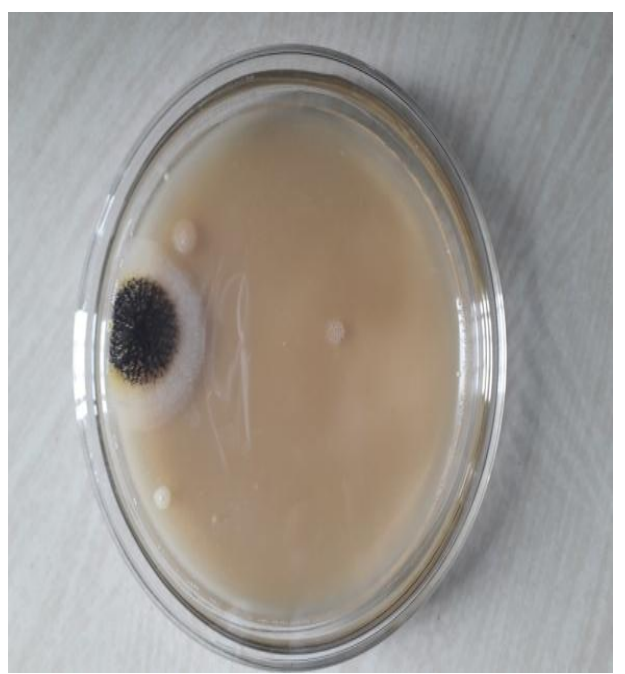

Fig.2 Aspergillus niger on SDA plate



Fig.4 Candida spp. on Gram staining 
In case of Streptococcus spp. isolates antibiotics like ciprofloxacin, cephalexin, gentamicin, neomycin, chloramphenicol, amoxycillin/clavulanic acid showed inhibitory zone of $19,19,11,11,18$ and $18 \mathrm{~mm}$ respectively. In case of E. Coli antibiotics like ciprofloxacin, gentamicin, polymyxin B, neomycin, chloramphenicol, tobramycin, amikacin showed inhibitory zone of 20, 13, 10, 14, 16, 13 and $17 \mathrm{~mm}$ respectively. Similarly, in case of Aspergillus spp.antifungals like fluconazole $(10 \mathrm{mcg})$, voriconazole $(1 \mathrm{mcg})$, mionazole (30mcg) showed minimum inhibitory zone of 20, 17 and $27 \mathrm{~mm}$ respectively where as in case of Candida spp. they showed 22, 18 and $26 \mathrm{~mm}$ respectively. Inhinitory zone of different antimicrobials can be found in Table 3 .

Corneal infection are usually treated with broad spectrum antibiotics before the culture sensitivity and antimicrobial susceptibility testing. Therefore knowledge regarding the microbial prevalence and its sensitivity profile is important for correct administration of therapy.

\section{References}

Andrew SE, DVM and DACVO (2003) Corneal Fungal Disease in Small Animals. Clinical Techniques in Small Animal Practice, vol 18, No 3 (August): pp 186192

Bauer AW, Kirby WM and Sherris JC (1966) Antibiotic susceptibility testing by a standardized single disk method. American Journal of Clinical Pathology, 45:493-496

CLSI. Reference method for antifungal disk diffusion susceptibility testing of yeasts; approved guideline-second edition. CLSI document M44-A2, 2009.
Furiani N, Scarampella F, Martino PA, Panzini§ I, Fabbri§ E and OrdeixL (2011) Evaluation of the bacterial microflora of the conjunctival sac of healthy dogs and dogs with atopic dermatitis. Veterinary Dermatology, 22, 490-496

Hindley KE, Groth AD, King M, Graham K and BilsonFM (2016) Bacterial isolates, antimicrobial susceptibility, and clinical characteristics of bacterial keratitis in dogs presenting to referral practice in Australia. Veterinary Opthalmology, 19, 5, 418-426

Kaye S, Tuft S, Neal T, Tole D, Leeming J, Figueiredo F, Armstrong M, McDonnell P, Tullo A, and Parry C (2009) Bacterial Susceptibility to Topical Antimicrobials and Clinical Outcome in Bacterial Keratitis. Investigative Ophthalmology \& Visual Science, Vol. 51, No. 1

Lin T and Jones SMP (2007) Antibiotic susceptibility of bacterial isolates from corneal ulcers of dogs in Taiwan. Journal of Small Animal Practice, 48, 271-274

Ollivier FJ and DVM (2003) Bacterial Corneal Diseases in Dogs and Cats. Clinical Techniques in Small Animal Practice, vol 18, No 3 (August): pp 193-198

Pucket JD, Allbaugh RA, Rankin AJ (2012) Treatment of dematiaceous fungal keratitis in a dog. Journal of the American Veterinary Medical Association; 240: 1104-1108

Samuelson DA, Andresen TL and GwinRM (1984) Conjuctival fungal flora in horse, cattle, dogs and cats. L Am Vet Med Assoc 184:1240-1242

Wayne PA (2009) Clinical and Laboratory Standards Institute (CLSI) performance standards for antimicrobial disk diffusion susceptibility tests $19^{\text {th }}$ ed. approved standard. CLSI document, M100-S19

\section{How to cite this article:}

Sisir Das, Rajashree Mishra, Prasana Kumar Rath, Bidyutprava Mishra, Chinmoy Mishra and Behera, S.S. 2019. Antimicrobial Sensitivity Profile of Eye Infection in Dogs. Int.J.Curr.Microbiol.App.Sci. 8(08): 505-511. doi: https://doi.org/10.20546/ijcmas.2019.808.058 